\title{
Correction of Facial Esthetics: A Case Series
}

\section{Lokesh Tomar*, Ekta Choudhary, Pooja Kabra and Rajat Bhandari}

Sharda University, Greater Noida, UP, India

\begin{abstract}
Esthetic dentistry has become one of the main areas of dental practice emphasis and growth for several years Patients are increasingly seeking treatment for their oral condition with the primary concern of an esthetic enhancement. A smile design should always include the evaluation and analysis of both facial and dental composition keeping in mind "Golden Proportion". Owing to improvements in physical and mechanical properties, particularly wear resistance, composite resins have overpowered silver amalgam as a choice of restorations in modern era. With advent of ceramic restorations (crowns and bridges, veneers), advancement in bleaching technologies, it has become easy to meet the expectations of patients. A beautiful smile, not just beautiful teeth delineates the importance of facial esthetics with botox, dermal fillers, threads which has now been tremendously used in advance esthetic dentistry. This presentation highlights on key elements for fruitful esthetic era.
\end{abstract}

Keywords: Esthetic; Veneer; Composites; Dermal filler; Botox.

\section{Introduction}

One of major esthetic concern for patients in today's era is the presence of a midline diastema or spaces in between anterior teeth [1]. Diastema is any space or gap greater than $0.5 \mathrm{~mm}$ between the central incisor. It is one of the most common form of incomplete occlusion seen more frequently between maxillary incisors than the mandibular incisors [2]. The etiology of maxillary diastema is believed to be multifactorial. They may vary from being physiological to various development anomalies of teeth and its associated oral tissue, prolonged abnormal oral habit, loss of equilibrium of oral musculature, maxillary midline pathology, periodontitis and abnormal structures of maxillary arch. Appropriate technique and material for effective treatment are based on time, physical, psychological and economical limitations [3]. The case series is describe management of esthetics- dental esthetics

Case 1) midline Case 2) peg lateral- facial esthetics Case 3) gummy smile

\section{Case Series}

\section{Case 1: Midline diastema}

A 23 old female reported at the Out Patient Department (OPD) of conservative and endodontics at Sharda hospital SDS having chief complain of space among maxillary anterior teeth (Figure 1). On examination uneven space between maxillary central incisor and between lateral incisor and canine on both right and left side was noted (Figures 2-4) the gap was approximately $1.5 \mathrm{~mm}$ between central and lateral incisor and $2 \mathrm{~mm}$ between central incisors [4].

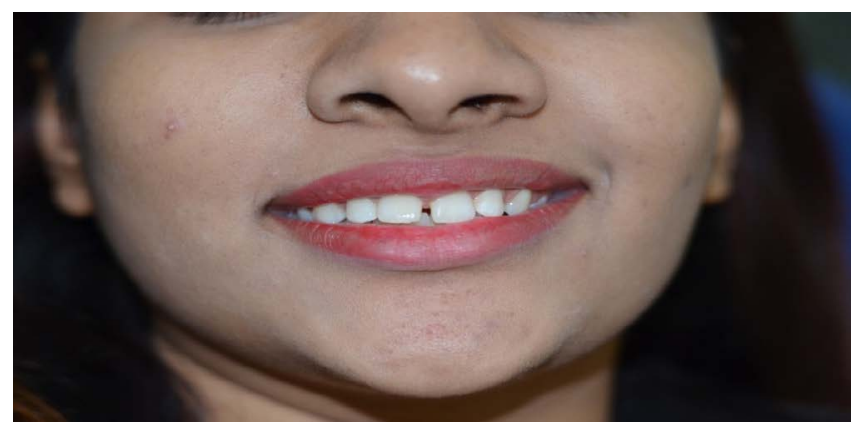

Figure 1: Preoperative picture.

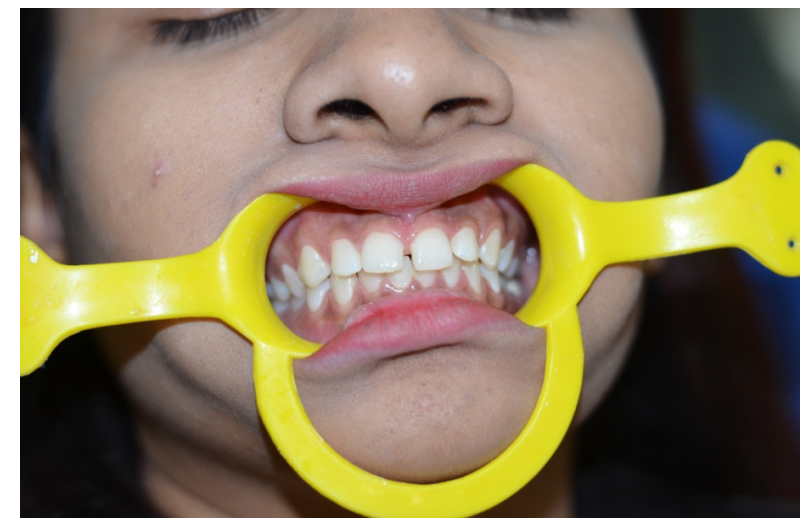

Figure 2: Pre-operative front picture.

To fabricate casts, impression were made using irreversible hydrocolloid material (Figures 5 and 6). A wax mock up was done corresponding to the patients facial and dental midline on cast. Patient was shown the mock up results and patient consent was taken for further treatment. Patient preparation was done and the area for the mock was scalled, isolate with rubber dam.

Central incisors were retracted by using retraction cord. Shade selection was considered A2 shade of vita guide teeth to be restored. Mesiolabial surface of tooth were flattened and beveling by using tapered diamond bur (acurata Germany) rinse with water and dry. The enamel on the mesial surface of central incisor was etched with $30 \%$ phosphoric acid (N- ethchivoclarvivadent) for 30 seconds. After rinsing and drying bonding agent (tertric $\mathrm{N}$-Bond, ivoclarvivodent) was applied and cured for 10 seconds (Figure 7) using LED curing unit. The first composite layer was applied using nano-hybrid composite with the help of silicon putty index as a guide (Figure 8). The adjacent tooth was separated by using mylar strips and layering technique use to stimulate natural tooth

*Corresponding author: Lokesh Tomar, Sharda University, Greater Noida, UP India, Tel: +91- 9870216674; E-mail: tomarlokesh2424@gmail.com

Received May 30, 2018; Accepted June 20, 2018; Published June 26, 2018

Citation: Tomar L, Choudhary E, Kabra P (2018) Correction of Facial Esthetics: A Case Series. Dentistry 8: 497. doi:10.4172/2161-1122.1000497

Copyright: $\odot 2018$ Tomar L, et al. This is an open-access article distributed under the terms of the Creative Commons Attribution License, which permits unrestricted use, distribution, and reproduction in any medium, provided the original author and source are credited. 


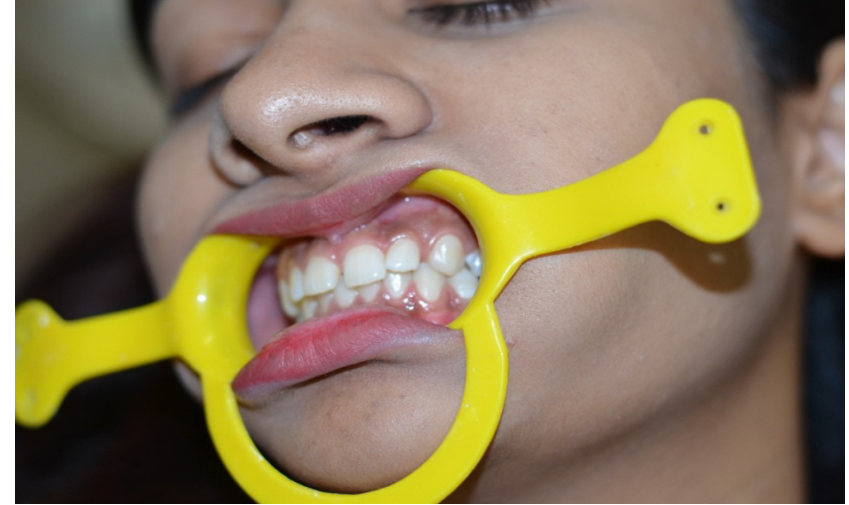

Figure 3: Pre-operative side view.

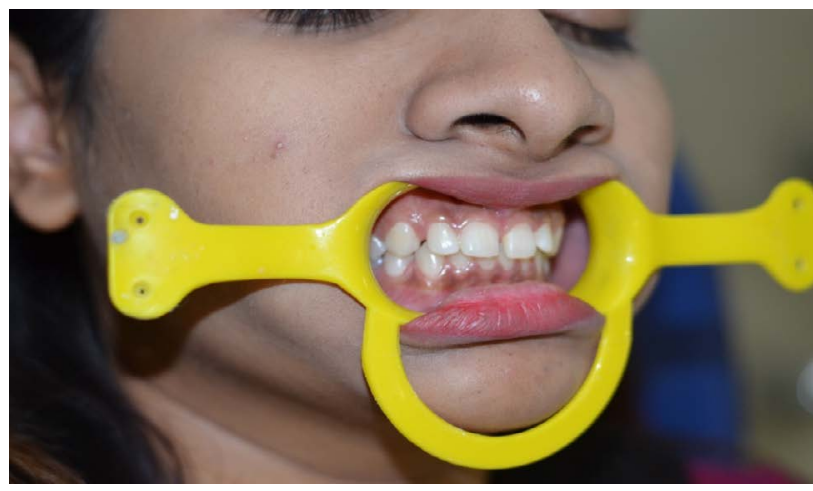

Figure 4: Pre-operative side view.

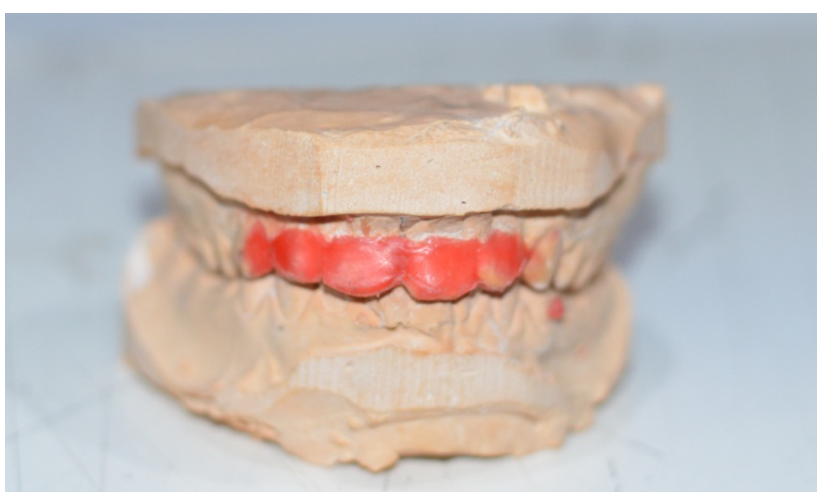

Figure 5: Diagnostic cast front view.

colour and translucency. Each layer was light cured for 40 seconds each from facial and lingual directions. Final layering was done till desired anatomy of tooth was achieved.

Finishing and polishing of restoration was done with polishing disc (microdont) in sequence (Figure 9). Other spaces were closed with same technique. Patient follow up was done at 1 week, 1 month till 6 month interval.

\section{Case 2: peg lateral- facial esthetics}

A 25 year old male reported at the Out Patient Department (OPD) of conservative and endodontics at Sharda hospital SDS having chief complain of disfigured tooth and desired reshaping of upper left anterior tooth. Isolation and preparation was done with the help of tapered diamond bur (acuratagermany). Rinse and dry the surface, the enamel was etched with $30 \%$ phosphoric acid for 30 second [4]. Bonding agent applied and cured with LED. Each layer of composite cured $40 \mathrm{sec}$ from all directions and final layering depicts the anatomy of tooth was desired. Finishing and polishing was done with disc (microdont). The case was followed up for 6 months (Figures 10 and 11).

\section{Case 3: Gummy smile}

A 31 year old female reported at the Out Patient Department (OPD)

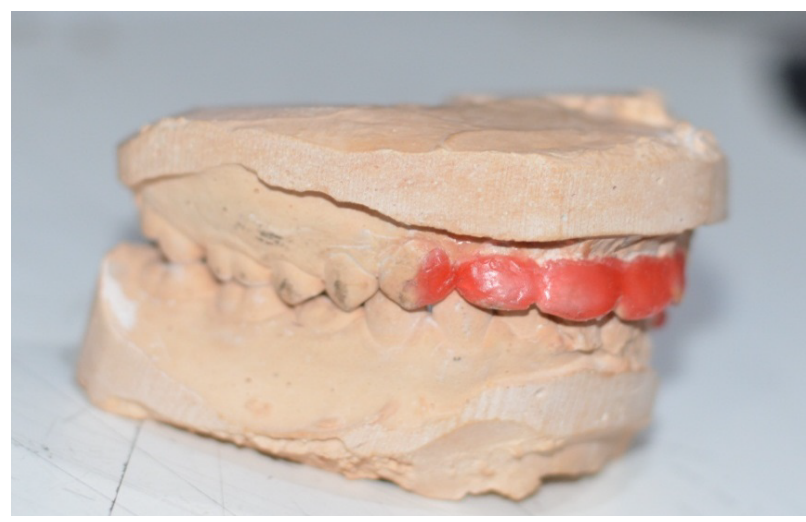

Figure 6: Diagnostic cast side view.

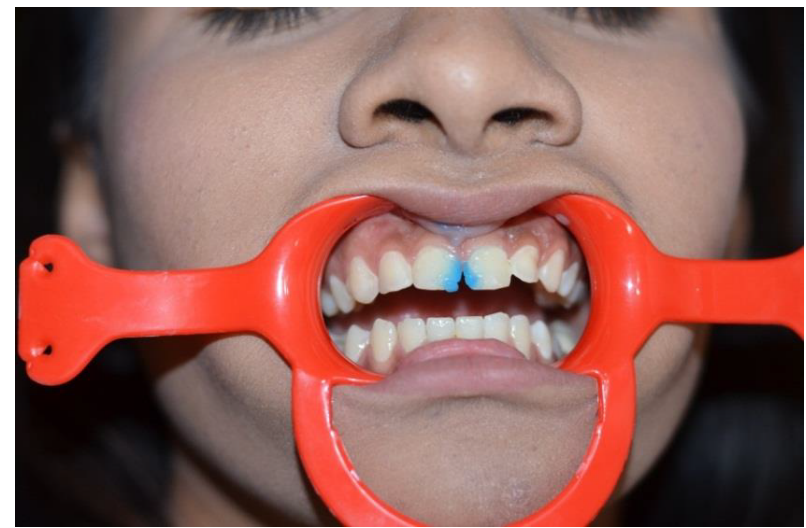

Figure 7: Shows use of etchant.

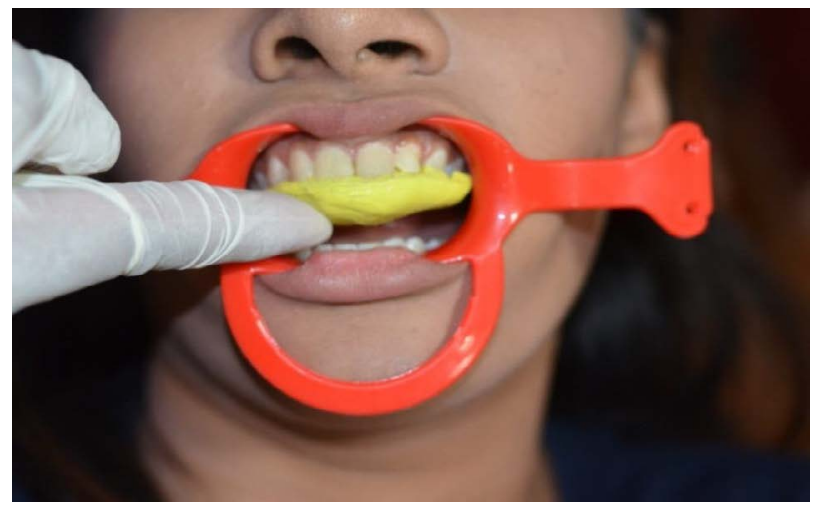

Figure 8: Try in of silicone putty index. 


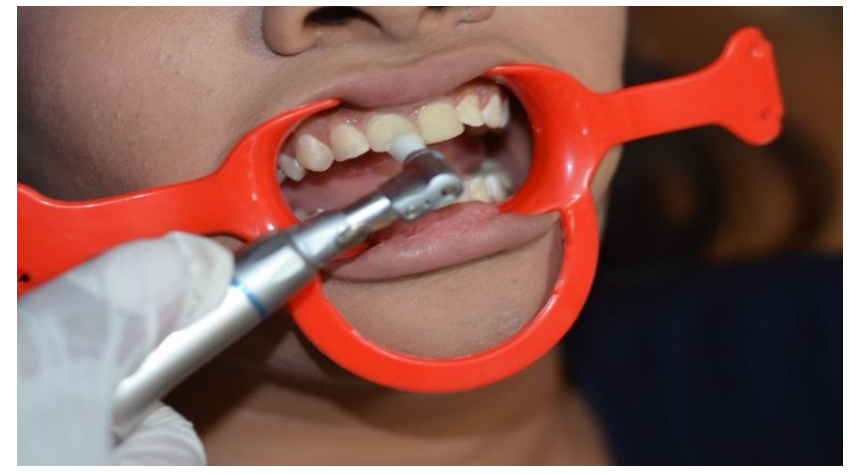

Figure 9: Polishing of restoration.

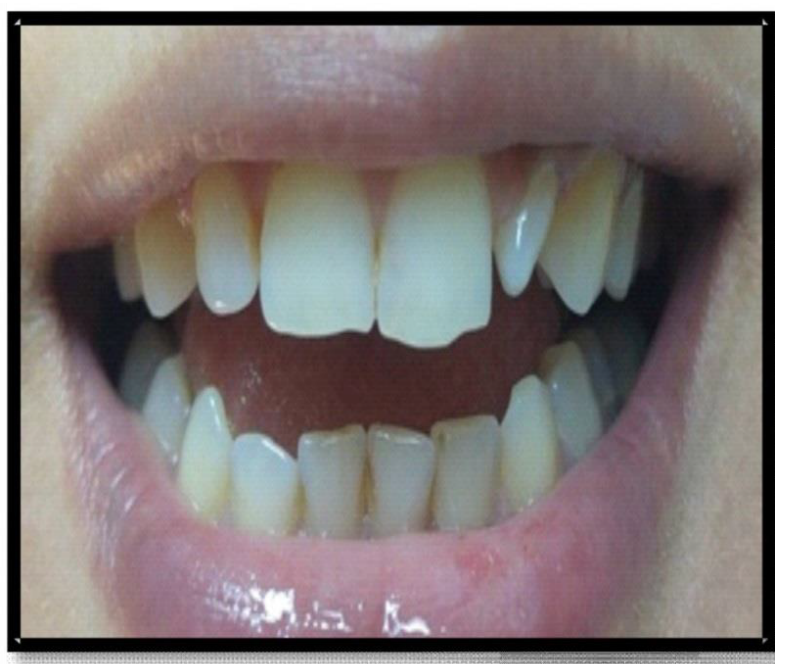

Figure 10: Shows peg lateral.

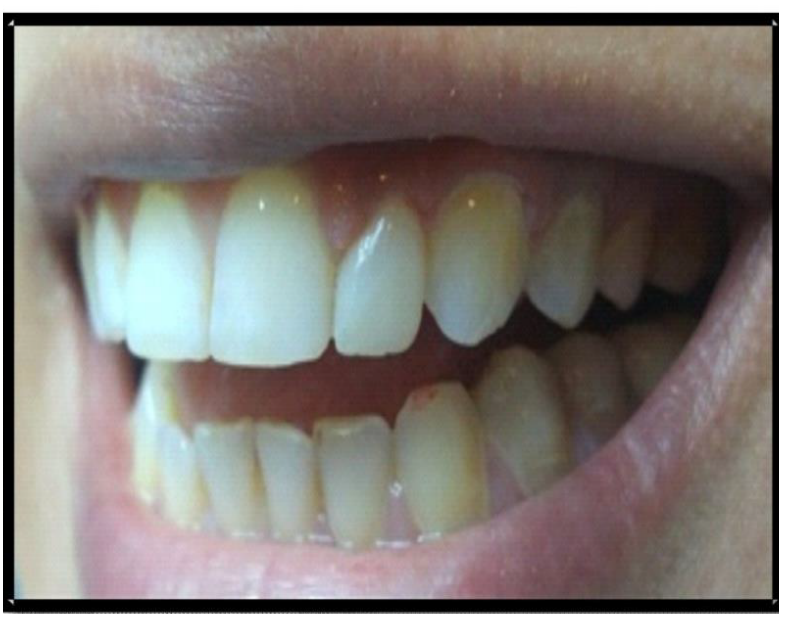

Figure 11: Finished restoration.

at Sharda hospital SDS with chief complains of gums been visible when patient smile, on examination it was found approximately $3 \mathrm{~mm}$ exposure of gum which brought patient slightly alarmed for her
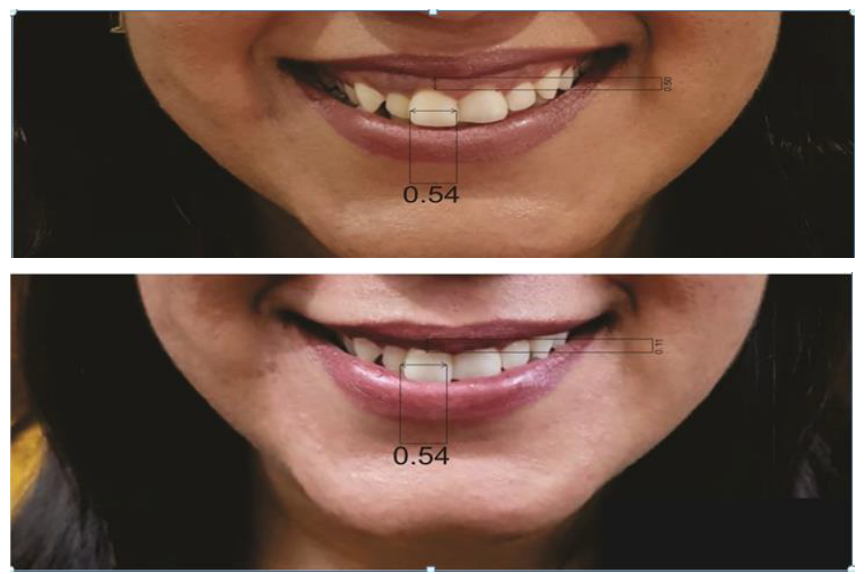

Figure 12: Patient with mixed gummy smile, before and after botulium toxin treatment.

esthetics. So it was decided to treat the gummy smile by Botulium Toxin (BT).

\section{Indication $[5,6]$}

Simple, fast and effective method, low risk, small doses, reversible effect contraindication [7]. Pregnancy, neuro musculature disease, without surgical treatment, dilution technique, ptosis, jokerliksmile, difficulty in smiling and chewing. The esthetic of smile are influenced by- teeth, gum and lips $[8,9]$ and this exposure of more than $3 \mathrm{~mm}$ of gums called as gingival or gummy smile (GS).

\section{Classification}

Anterior, posterior mixed and asymmetrical. Here it is mixed GSwith excessive gum exposure in both anterior and posterior regions involving the action of a combination of two or more of muscles including LLSAN and ZM. The brand of BT was used abobutulium toxin A $500 \mathrm{IU}$ per vial, diluted in $2 \mathrm{ml}$ of $0.9 \%$ sodium chloride solution immediately before injection following the recommended guidelines on dilution storage [10]. Preoperative radiograph was taken, patient received topical anaesthesia with a cream containing lidocaine and prilocaine. For injection, $0.3 \mathrm{ml}$ syringe were used with a 31 gauge, $8 \mathrm{~mm}$ needle and abobotulium toxin A was injected into the subcutaneous tissue (Figure 12).

It is a two point lift, injecting of BTA in the malar region following a lateral and superior path (ZM) and zygomaticus minor- a) $1^{\text {st }}$ pointnasolabial fold (at greatest lateral contraction),b) $2^{\text {nd }}$ point $-2 \mathrm{~cm}$ lateral to the first at level of tragus,

At each point $2.5 \mathrm{IU}$ injected but dose was reduced $50 \%$ at the point near the nasal ala. Advised not to lie down, exercise or massage the treated are first 4 hour after procedure. Post-operative radiograph is taken and follow up after 20-30 days, examination by photography.

\section{Discussion}

In Case 2, Mock was done to pre access the outcome of reaction and ensure the patient about final results. Though it was favourable for ceramic veneering because of patient constraint composite veneers decided. As comparing the ceramic the colour stability of direct composite veneers is less as compared to glazed ceramic but definitely depend on finishing and polishing of composite which can prevent 
by repeated visiting. Layer technique is preferred over bulk because it will give well define proportion. Studies have shown that functional stability, esthetical, and economical involving less chair side time along with these the added advantage of direct composite veneering it can be easily repaired in case of fracture. So the present case was thought to be treated using good direct composite resin restoration meeting the esthetic demand of the patient at the same time managing time and money. Six month follow up of patient was done to check with esthetics and incisor didn't reveal any discolouration.

Case 3, Goldstein classified smile line- high, medium, low [11]. In men- 2:5:1, women (2:1) by Tjan et al. [12]. Peck et al. [13] patient with gs had atleast $20 \%$ greater facial muscular capacity to raise the upper lip when smiling. LLSAN function is to dilate the nostril and raise the upper lip and in some cases ZM more involved and conventional application of BT to relax the LLSAN muscle should cause unnecessary lowering of the lip in the middle region an undesirable result from esthetic and functional stand point [14].

$\mathrm{ZM}$ causes elevation and lateralization of lateral portion of the upper lip. So help in smile, speech and chewing at small dose.

BT spread halo so diameter of halo depends mainly on the dilution used and depth of injection. When there is a need to treat muscle groups with synergistic effect in relation to lip movement, the dose injection in each muscle should be lower than (50\% reduction) those conventionally recommended because of risk of an accumulative relaxation effect and resulting complications as required in mixed gummy smile.

By several application of BT, the effect has declined, this was explained by decrease in muscle strength that is likely to occur after several consecutive application of BT. Precaution is important for such cases. Correct dose equivalence to be less than $3 ; 1[15,16]$ and injection should be made by an experience physician with good anatomic and physiologic knowledge of facial musculature.

\section{Conclusion}

In Case 2, the painless conservative approach resulted in complete patient satisfaction leading to a surface outcome. Long term follow of such cases is important to assess the drawback of direct composite resin.

Case 3 , there is $90 \%$ decrease in gum exposure.

Adverse effects sad smile curable by 5 IU in these muscles and duration of effect is 3 to 5 months. To identify the type of smile, the main muscles involved, so that the correct injection technique can be used. Abobotulinumtoxin $\mathrm{A}$ is effective and use in the middle third of the face when the dose, the correct injection point is used.

\section{References}

1. Wolff D, Kraus T, Schach C, Pritsch M, Mente J, et al. (2010) Recontouring teeth and closing with direct composite buildups: aa clinical evolution of survival and quality parameters. J Dent 38: 1001-1009.

2. Keene HJ (1963) Distribution of diastemas in the dention of man. Am J Phys Anthropol 21: 437-441.

3. Kim YH, Cho YB (2011) Diastema closure with direct composite architectural gingival contouring. J Koren Acad Conserv Dent 36: 515-520.

4. Heymann HO, Hershey HG (1985) Use of composite resin for restorative and orthodontic correction of anterior interdental spacing. J prosthet dent 53: 766-771.

5. Polo M (2008) Botulinum toxin type A (Botox) for the neuromuscular correction of excessive gingival display on smiling (gummy smile). Am J Orthod Dentofacial orthop 133: 195-203.

6. Carreuther AS, Carruther J (1998) Cosmetic uses of botulinum A exotoxin In Kelin AW, editor. Tissue augmentation in clinical practice: procedures and technique. New York; Marcel Dekker pp 207-236.

7. Carruthers A, Carruther JDA (1994) Botulinum toxin in the treatment of glabelle frown lines and other facial wrinkles. In: New York: Marcel Dekker. Pp. 577-595.

8. Garber DA, Salama MA (1996) The aesthetic Smile: Diagnosis and treatment. Periodontrol 2000 11: 18-28.

9. Gill DS, Naini FB, Tredwin CJ (2008) Smile aesthetic. SADJ 63: 272-275.

10. Klein AW (1998) Dilution and storage of Botulinum toxin. Dermatol Surg 24: 1179-1180.

11. Goldstein RE, Editor (1976) Esthetics in dentistry. Philadeltila JB Lippincott Co.

12. Tjan AH, Miller GD (1984) Some esthetic factors in a smile. J Prosthet Dent 51: $24-28$

13. Peck S, Peck L, Kataja M (1992) The Gingival smile line. Angle orthod 62 91-100.

14. Gest TR, Schlesinger J, editors (1995) Medcharts anatomy. New York ILOC Inc.

15. Karsai S, Raulin C (2009) Current evidence on the unit equivalence of different Botulinum Neurotoxin A Formulations and Recommendations for Clinical Practice in Dermatology. Dermatol Surg 35: 1-8.

16. Wohlfarth K, Schwandt I, Wegner F, Jurgens T, Gelbrich G, et al. (2008) Biological activity of two botulinum toxin type A complexex (Dysport and Botox) in volunteers. J neurol 255: 1932-1939. 